\title{
PROPOSAL PROYEK PENGEMBANGAN APLIKASI SISTEM INFORMASI AKADEMIK SEKOLAH
}

\author{
NAMA : Meriska Hamni \\ NIM : 0702202100 \\ KELAS : Sistem Informasi 4
}

MATA KULIAH : Sisitem Informasi Manajemen DOSEN PENGAMPU : Dr. YAHFIZAM, S.T.,M.CS

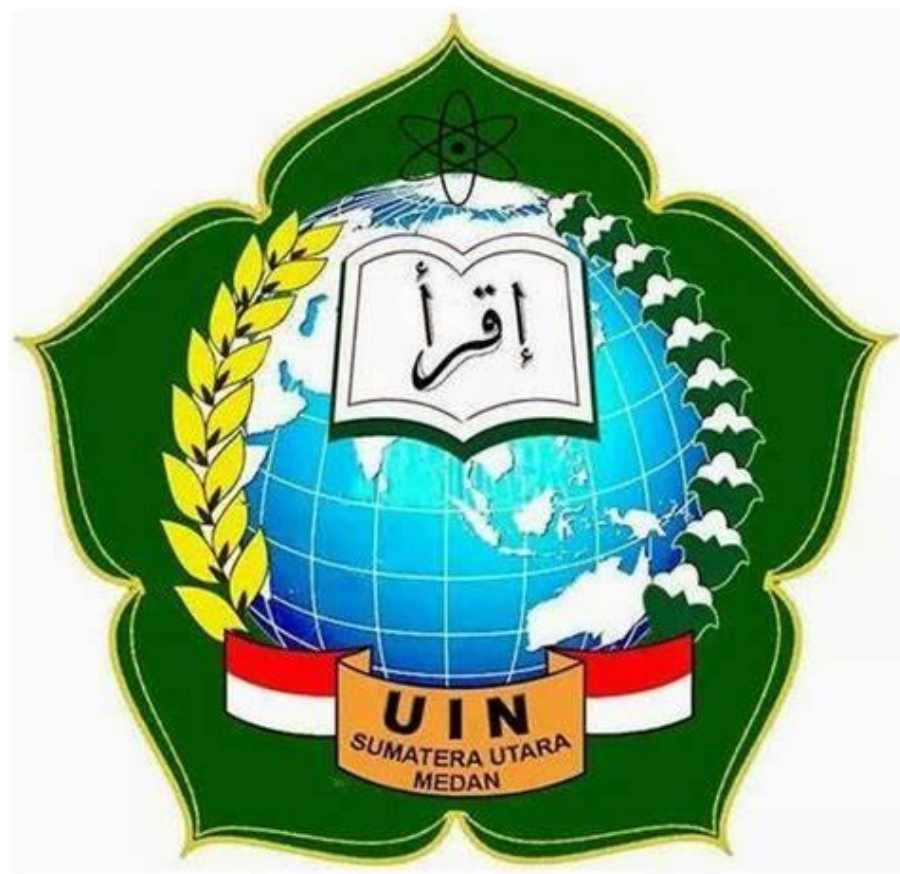

FAKULTAS SAINS DAN TEKNOLOGI

UNIVERSITAS ISLAM NEGERI SUMATERA UTARA 2021 


\section{A. LATAR BELAKANG}

Sekolah mengemban tugas untuk memberikan pelayanan pendidikan kepada masyarakat khususnya kepada anak-anak berumur di bawah 18 tahun dengan lebih baik dan lebih profesional. Sekolah Sebagai salah satu lembaga pendidikan, sekolah memiliki kewajiban untuk terus meningkatkan kinerja dan kualitas kerjanya. Publisitas, khususnya siswa/i dan karyawan.

Untuk memenuhi persyaratan tersebut, kami menyediakan aplikasi Sistem Informasi Akademik Sekolah (SIAS) berbasis web untuk mempermudah pengelolaan informasi sekolah dan menyebarluaskan informasi ke tujuan dan memudahkan akses. pengunjung website memiliki akses internet. Aplikasi ini juga dapat digunakan sebagai homepage untuk menyampaikan informasi tentang sekolah.

\section{B. MAKSUD DAN TUJUAN}

Aplikasi ini dirancang untuk memudahkan pengumpulan dan pengelolaan informasi sekolah oleh bagian administrasi. Guru dan siswa juga dapat belajar tentang tanggal dan hasil tes. Sejauh ini, informasi tentang tes dan hasil telah dikirim secara lisan atau melalui surat penjualan di forum. Menggunakan database untuk menyimpan data penting ini dapat mengurangi kemungkinan kehilangan atau kerusakan data.

\section{KEUNTUNGAN}

Keunggulan.Sistem.Informasi.Sekolah(SIAS).adalah:

\section{A.Sekolah:}

1. Dapat menyimpan dan mengolah data penting sekolah secara akurat dan mudah tanpa usaha.Mengurangi kebutuhan akan kertas dan alat tulis, serta ruang tempat menyimpan data.

1. Mempermudah dan mempercepat pekerjaan dari bagian administrasi sekolah.

2. Meningkatkan pelayanan dan citra sekolah di masyarakat dan menjadi sekolah unggulan dan pemimpin teknis. 


\section{a. Guru :}

1. Memudahkan guru untuk menyimpan nilai siswa dan mengurangi kemungkinan kehilangan poin karena hilangnya sumber data (kertas).

2. Proses transfer informasi menjadi lebih cepat, mudah dan murah.

b. Siswa :

1. Selama ada jaringan, Anda dapat mengakses informasi kapan saja dan di mana saja.

2. Anda dapat menyimpan dan mencetak rencana dan hasil pemeriksaan.

\section{KEUNGGULAN SISTEM}

Sistem Informasi Akademik Sekolah (SIAS) memberikan beberapa keunggulan dan tentunya akan mendukung dan mempermudah proses pengolahan data sekolah dan pemberian.informasi.Keunggulan.sistem.kami

1. Penggunaan teknologi informasi dapat membantu mengurangi penggunaan kertas sebagai.bahan.untuk.mencetak.dokumen.

2. Penggunaan sistem database terkomputerisasi akan membuat pengolahan data lebih efisien dan mengurangi ruang yang dibutuhkan untuk menyimpan data dan file pelatihan. 3.Data.lengkap,mudah.diakses.dan.mudah.dikelola.

4.Menghemat.biaya.pemeliharaan.adalah.investasi.jangka.panjang.

5. Dapat dimodifikasi sesuai kebutuhan dan diintegrasikan ke dalam sistem informasi yang ada.

\section{E. METODOLOGI PENGEMBANGAN SISTEM}

1. Metode SDLC (System Development Life Cycle) digunakan untuk pengembangan sistem informasi ini. SDLC, atau lebih dikenal sebagai siklus hidup pengembangan sistem, adalah proses membuat atau mengembangkan sistem menggunakan model dan metode tertentu. Berbagai tahapan metodologi pengembangan tercantum di bawah ini. Sistem diimplementasikan menggunakan metode prototipe pengembangan sistem Web untuk

SIAS,

yaitu:

\section{Fase,Perencanaan}

Fase ini mengidentifikasi potensi masalah dalam proyek pengembangan sistem dan mengkonfirmasi apakah itu layak. Pada tahap ini juga dirumuskan jadwal pengembangan proyek yang direncanakan.Tahap Analisis 
Informasi, data dan arsip dikumpulkan sebagai acuan untuk menentukan kebutuhan sistem. Membangun prototipe sebagai model awal tampilan sistem.

2.Tahap.desain

Mengembangkan alur kerja sistem dan tampilan sistem, dan kemudian menggunakannya.sebagai.prototipe.

3.Tahap.implementasi.ketiga

Menginstal sistem, menguji dan memverifikasi Data masukan dan mengubahnya menjadi database Membuat dokumen atau laporan untuk pemantauan atau pemeliharaan.

\section{F. STUDI KELAYAKAN}

1.Kelayakan Operasi Untu menjalankan sistem ini tidak diperlukan tenaga atau user yang benarbenar ahli.Sistem mudah dioperasikan bahkan oleh orang yang awam terhadap teknologi.

\section{Kelayakan Teknis}

Sekolah memiliki fasilitas dan sumber daya yang memadai, seperti pembelian peralatan bantu, sehingga sistem dapat beroperasi secara normal.

\section{Kelayakan Ekonomi}

Sistem ini memiliki biaya konstruksi yang rendah, biaya perawatan dan dukungan yang rendah.

1.Pekerjaan pada sistem akan selesai dalam waktu dua bulan dan dapat segera digunakan.

\section{G. RANCANGAN SISTEM}

Sistem informasi akademik ini dirancang dan dibangun dengan PC (personal computer) yang terhubung dengan database. Proses bisnis SIAS adalah sebagai berikut:

1. Sistem memiliki beberapa pengguna dengan izin yang berbeda, termasuk administrator, guru, siswa, dan pengguna lainnya.Sistem akan merekam proses penyimpanan data yang berhubungan dengan informasi yang diperlukan dan digunakan oleh sekolah tersebut..

2. Untuk memproses data dan melakukan aktivitas lain melalui sistem, pengguna harus login terlebih dahulu. Pengguna tidak memiliki hak untuk mengubah nama pengguna atau kata sandi login, dan harus menghubungi administrator 
terlebih dahulu. Ini mencoba untuk memantau penyusup atau peretas dan mencegah mereka memasuki sistem.Administrator atau admin memiliki hak akses penuh akan sistem ini, namun ketika ingin menginputkan data nilai siswa apabila Jika tidak ada guru, administrator harus mengaksesnya melalui akun guru mata pelajaran yang bersangkutan.

3. Guru berhak memasukkan data nilai dan data biologis siswa.Siswa hanya dapat melihat nilai, jadwal, jadwal ujian, dan menginputkan biodata.

Pengembangan aplikasi SIAS ini membutuhkan perangkat keras dan perangkat lunak untuk mendukung pengoperasian sistem, misalnya::

Tabel 1. Spesifikasi Hardware dan Software

\begin{tabular}{|l|l|}
\hline \multirow{2}{*}{ Hardware } & $\begin{array}{l}\text { PC Intel Processor Pentium III dan seri } \\
\text { diatasnya } \\
\text { OS Windows 2000 / XP / 7 atau Linux } \\
\text { RAM minimal 128 MB } \\
\text { Hard Disk 40 GB } \\
\text { Printer }\end{array}$ \\
\hline \multirow{2}{*}{ Software } & MySQL \\
\cline { 2 - 3 } & PHP \\
\hline
\end{tabular}

Data-data yang diperlukan dalam sistem adalah :

1. Data siswa

2. Data karyawan

3. Data nilai

4. Data jadwal

5. Data ruang

6. Data jadwal ujian

7. Data mata pelajaran 


\section{H. STAFF}

Personil atau personel yang terlibat dalam pengembangan sistem ini:

1. Analis Sistem: Berpartisipasi dalam analisis permintaan sistem sesuai dengan kebutuhan pelanggan dan pengguna, dan merencanakan pembangunan sistem pada saat yang bersamaan.

2. Desainer: Membuat desain sistem yang dibuat oleh analis sistem, termasuk proses dan tampilan.

3. Programmer: Berdasarkan sistem konstruksi proyek perancang.

\section{RANCANGAN BIAYA}

Berikut adalah rincian dari rancangan biaya pengembangan aplikasi ini :

Tabel 2. Hardware

\begin{tabular}{|c|c|c|c|}
\hline NO. & KETERANGAN & $\begin{array}{c}\text { JUMLAH } \\
\text { BARANG }\end{array}$ & $\begin{array}{c}\text { HARGA } \\
\text { (Rp) }\end{array}$ \\
\hline 1 & PC & 1 & 4.000 .000 \\
\hline 2 & Printer & 1 & 1.500 .000 \\
\hline \multicolumn{3}{|c|}{ TOTAL } & $\mathbf{5 . 5 0 0 . 0 0 0}$ \\
\hline
\end{tabular}

Tabel 3. Software

\begin{tabular}{|c|c|c|c|}
\hline NO. & KETERANGAN & $\begin{array}{c}\text { JUMLAH } \\
\text { BARANG }\end{array}$ & $\begin{array}{c}\text { HARGA } \\
\text { (Rp) }\end{array}$ \\
\hline 1 & $\begin{array}{c}\text { OS Windows XP } \\
\text { (Original) }\end{array}$ & 1 & 1.500 .000 \\
\hline 2 & $\begin{array}{c}\text { Instalasi } \\
\text { APACHE + } \\
\text { MySQL }\end{array}$ & 1 & 500.000 \\
\hline \multicolumn{3}{|c|}{ TOTAL } & $\mathbf{2 . 0 0 0 . 0 0 0}$ \\
\hline
\end{tabular}


Tabel 4. Tenaga Kerja

\begin{tabular}{|c|c|c|}
\hline NO. & KETERANGAN & HARGA \\
$(\mathbf{R p})$
\end{tabular}

Tabel 5. Biaya Kegiatan

\begin{tabular}{|c|c|c|c|}
\hline \multicolumn{4}{|c|}{ BIAYA PROYEK } \\
\hline & \multicolumn{2}{|c|}{ A. Tahap Perencanaan dan Analisis } & \\
\hline s & Transportasi & 1.000 .000 & \\
\hline 1 & Komunikasi & 250.000 & \\
\hline can & Konsumsi & 250.000 & \\
\hline c & Biaya Dokumentasi (kertas,fotokopi,print,dll) & 500.000 & \\
\hline \multicolumn{3}{|c|}{ Total Tahap Biaya Analisis } & 2.000 .000 \\
\hline & \multicolumn{2}{|c|}{ B. Tahap Desain } & \\
\hline s & Biaya Dokumentasi (kertas,fotokopi,print,dll) & 500.000 & \\
\hline \multicolumn{3}{|c|}{ Total Biaya Tahap Desain } & 500.000 \\
\hline & \multicolumn{2}{|c|}{ C. Biaya Training } & \\
\hline s & Biaya Dokumentasi (kertas,fotokopi,print,dll) & 500.000 & \\
\hline 1 & Konsumsi & 200.000 & \\
\hline cis & Transportasi & 200.000 & \\
\hline \multicolumn{3}{|c|}{ Total Biaya Training } & 900.000 \\
\hline
\end{tabular}




\begin{tabular}{|c|c|c|c|}
\hline & \multicolumn{2}{|c|}{ D. Tahap Support, Testing dan Perawatan } & \\
\hline & Biaya Personil & 1.000 .000 & \\
\hline $\mathrm{b}$ & $\begin{array}{l}\text { Biaya Perawatan Perangkat Keras } \\
\text { (reparasi,servis) }\end{array}$ & 1.000 .000 & \\
\hline c & Biaya Overhead (listrik, supplies) & 500.000 & \\
\hline d & Biaya tidak terduga & 1.000 .000 & \\
\hline Total Bia & a Support, Testing dan Perawatan & & 3.500 .000 \\
\hline
\end{tabular}

\section{J. PENJADWALAN}

Tabel 6. Penjadwalan Proyek

\begin{tabular}{|c|c|c|c|c|c|c|c|c|c|}
\hline \multirow{2}{*}{ No } & \multirow{6}{*}{ Tahapan Pekerjaan } & \multicolumn{6}{|c|}{ Jadwal Pelaksanaan } \\
\cline { 3 - 10 } & & \multicolumn{5}{|c|}{ Januari } & \multicolumn{4}{|c|}{ F } \\
\hline & & $\mathbf{1}$ & $\mathbf{2}$ & $\mathbf{3}$ & $\mathbf{4}$ & $\mathbf{1}$ & $\mathbf{2}$ & $\mathbf{3}$ & $\mathbf{4}$ \\
\hline 1 & Tahap Perencanaan & & & & $\sqrt{ }$ & & & & \\
\hline 2 & Tahap Analisis & & & & & $\sqrt{ }$ & & & \\
\hline 3 & Tahap Perancangan & & & & & & $\sqrt{ }$ & & \\
\hline 4 & Tahap Evaluasi & & & & & & & $\sqrt{ }$ & \\
\hline 5 & Tahap Implementasi & & & & & & & & $\sqrt{ }$ \\
\hline
\end{tabular}




\section{K. HASIL PENELITIAN}

1. Use Case Diagram

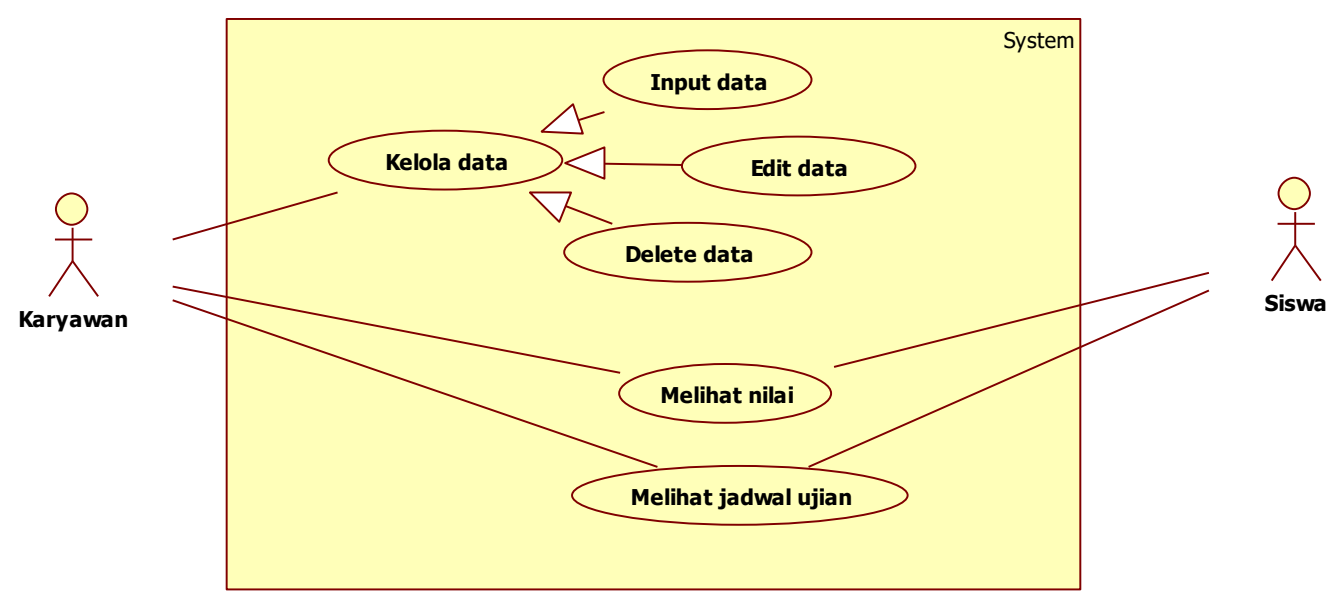

2. Kandidat Proses

\begin{tabular}{|l|l|}
\hline \multicolumn{1}{|c|}{ Aktor } & \multicolumn{1}{|c|}{ Keterangan } \\
\hline Karyawan & $\begin{array}{l}\text { Karyawan terdiri atas guru dan admin. Admin } \\
\text { memiliki hak kelola semua data sedangkan guru } \\
\text { hanya bisa memasukkan nilai. }\end{array}$ \\
\hline Siswa/i & $\begin{array}{l}\text { Seseorang yang punya hak akses untuk melihat } \\
\text { nilai siswa dan jadwal ujian }\end{array}$ \\
\hline
\end{tabular}

\begin{tabular}{|c|l|}
\hline Aktor & \multicolumn{1}{|c|}{ Keterangan } \\
\hline Karyawan & Login Admin \\
\hline & a. Kelola data siswa \\
\hline & Menginput data siswa \\
\hline & Mengedit data siswa \\
\hline & Menghapus data siswa \\
\hline
\end{tabular}




\begin{tabular}{|c|}
\hline Melihat data siswa \\
\hline b. Kelola data nilai \\
\hline Menginput data nilai \\
\hline Mengedit data nilai \\
\hline Menghapus data nilai \\
\hline Melihat data nilai \\
\hline c. Kelola data jadwal \\
\hline Menginput data jadwal \\
\hline Mengedit data jadwal \\
\hline Menghapus data jadwal \\
\hline Melihat data jadwal \\
\hline d. Kelola data karyawan \\
\hline Menginput data karyawan \\
\hline Mengedit data karyawan \\
\hline Menghapus data karyawan \\
\hline Melihat data karyawan \\
\hline e. Kelola data mata pelajaran \\
\hline Menginput data mata pelajaran \\
\hline Mengedit data mata pelajaran \\
\hline Menghapus data mata pelajaran \\
\hline Melihat data mata pelajaran \\
\hline f. Kelola data kelas \\
\hline Menginput data kelas \\
\hline Mengedit data kelas \\
\hline Menghapus data kelas \\
\hline Melihat data kelas \\
\hline
\end{tabular}




\begin{tabular}{|l|l|}
\hline & \\
\hline & g. Kelola data ruang \\
\hline & Menginput data ruang \\
\hline & Mengedit data ruang \\
\hline & Menghapus data ruang \\
\hline & Melihat data ruang \\
\hline & h. Kelola data jadwal ujian \\
\hline & Menginput data jadwal ujian \\
\hline & Mengedit data jadwal ujian \\
\hline & Menghapus data jadwal ujian \\
\hline & Melihat data jadwal ujian \\
\hline & \\
\hline & Login Guru \\
\hline & a. Kelola data nilai \\
\hline & Menginput data nilai \\
\hline & Mengedit data nilai \\
\hline & Menghapus data nilai \\
\hline & Melihat data nilai \\
\hline & \\
\hline & a. Punya hak akses melihat jadwal dan jadwal ujian \\
\hline & Melihat nilai \\
\hline
\end{tabular}


2. DFD Level 0 (Diagram Konteks)

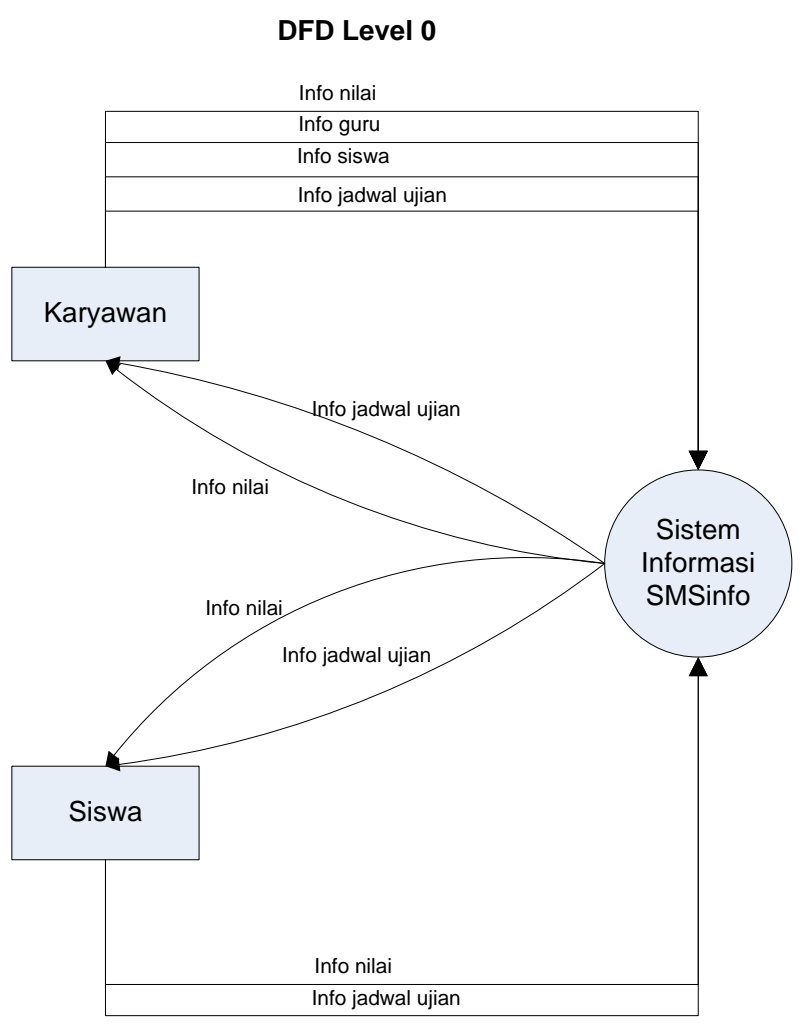




\section{DFD Level 1}

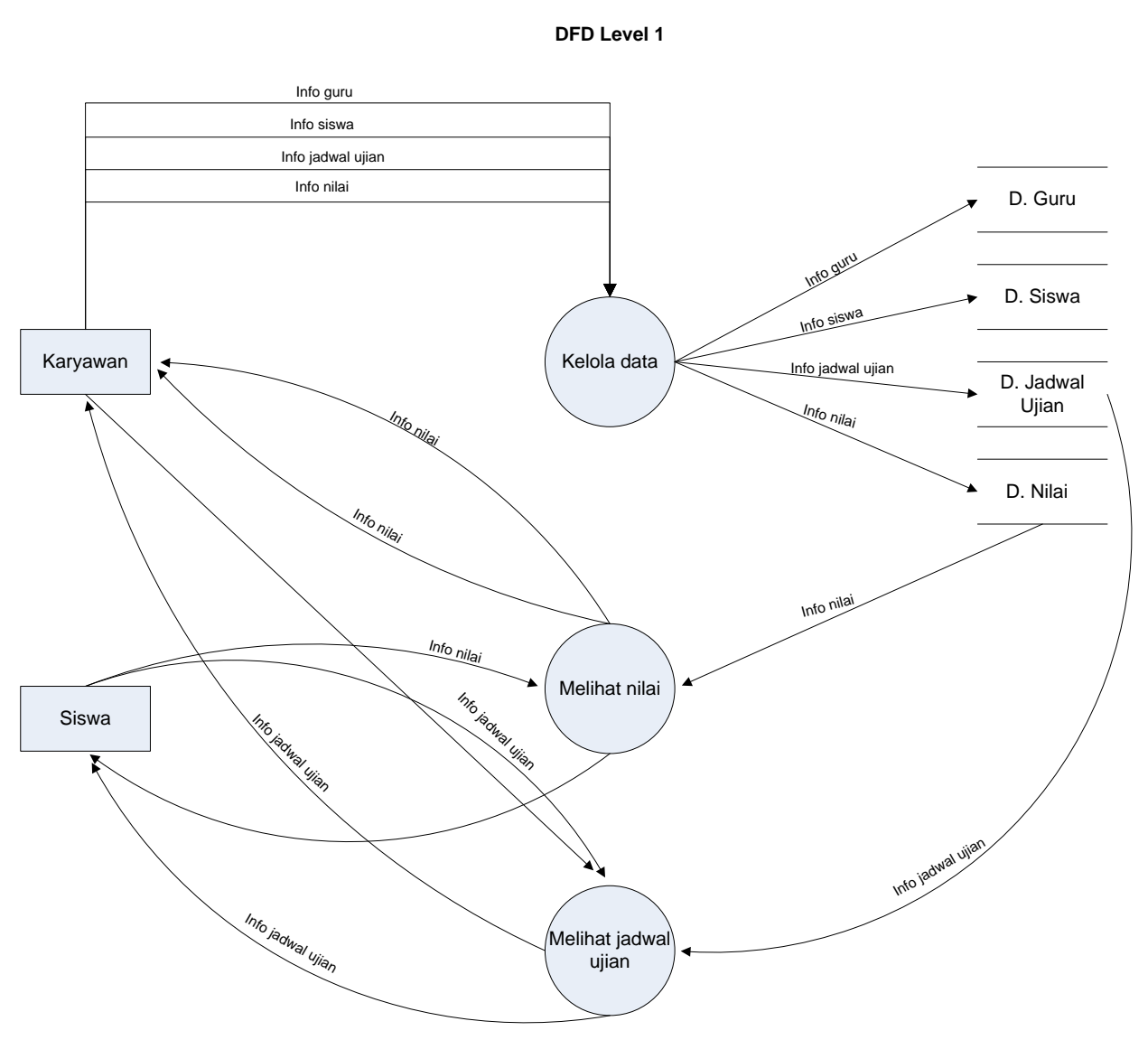


4. ERD

\section{ERD SISTEM INFORMASI AKADEMIK SEKOLAH}

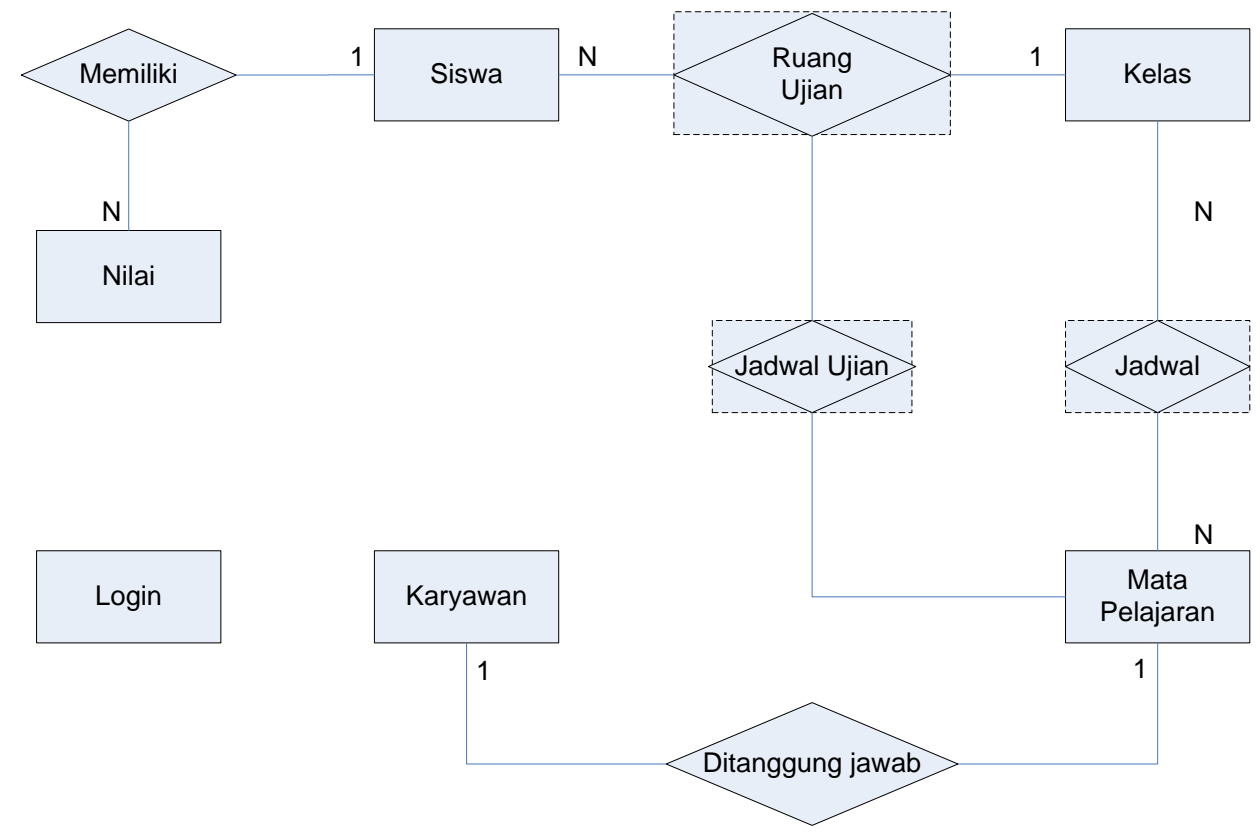

L. PENUTUP

Oleh karena itu, aplikasi proyek sistem informasi sekolah untuk tujuan promosi kegiatan sekolah diajukan untuk ditinjau. Saya berharap sekolah-sekolah di Indonesia semakin maju dan mampu bersaing dalam teknologi. 